\title{
Changes in cervical range of motion following anterior cervical discectomy with fusion - preliminary results
}

\author{
Bartosz Limanówka, Leszek Sagan \\ Department of Neurosurgery and Paediatric Neurosurgery, Pomeranian Medical University in Szczecin, Poland
}

\begin{abstract}
Background. The biomechanics of the cervical spine after anterior cervical discectomy with fusion (ACDF), and in particular changes in its global mobility, are phenomena that have not yet been sufficiently studied. Consequently, their effect on the eventual result of treatment is not fully understood. The aim of this study was to assess changes in global and segmental mobility of the cervical spine after ACDF.

Material and methods. 28 patients who underwent ACDF for cervical spondylosis were examined. The study was divided into two stages: preoperative and postoperative. Range of motion (ROM) was analysed based on $\mathrm{X}$-ray AP, lateral and functional images: $\mathrm{C1}-\mathrm{C} 7, \mathrm{C1}-\mathrm{C2}, \mathrm{C2}-\mathrm{C7}, \mathrm{C1}-\mathrm{C4}, \mathrm{C4}-\mathrm{C} 7$, and segments adjacent to the stabilisation. The patients were divided into groups depending on the length of spondylodesis and the occurrence of adjacent segment degeneration (ASDeg).

Results. A statistically significant difference was found in the total ROM of C2-C7, C1-C7 and C4-C7 after ACDF. The ROM of C2-C7 decreased by $23 \%$, of $\mathrm{C} 1-\mathrm{C} 7$ by $20 \%$, and of $\mathrm{C} 4-\mathrm{C} 7$ by $38 \%$. These changes occurred by reducing the extension ROM C2-C7 by $33 \%, \mathrm{C} 1-\mathrm{C} 7$ by $31 \%$, and C4-C7 by $12 \%$. There was a statistically significant (31\%) reduction in total ROM in the segment above ACDF, a $41 \%$ reduction in extension ROM of this level in the non-ASDeg group, and a $73 \%$ increase in the segmental extension ROM above ACDF in patients with ASDeg.

Conclusions. ACDF reduces the total ROM of the cervical spine in the sagittal plane. This change occurs by reducing the neck extension, and its severity depends on the length of the spondylodesis. In patients without ASDeg after ACDF, the mobility of the level above the stabilisation decreases. The occurrence of ASDeg is associated with a higher postoperative ROM of the segment located above the spondylodesis.
\end{abstract}

Key words: cervical spine, anterior cervical discectomy with fusion, range of motion, biomechanics

(Neurol Neurochir Pol 2020; 54 (6): 568-575)

\section{Introduction}

The consequences of anterior cervical discectomy with fusion (ACDF) have been of interest to researchers since this method was first developed. Biomechanical changes on the previously inoperable segments of the cervical spine have been noted. Adjacent segment disease (ASDz) is defined as the appearance of new, symptomatic degenerative changes at levels adjacent to the stabilisation. The concept of adjacent segment degeneration (ASDeg) refers to the occurrence of radiological changes without clinical manifestation [1]. This division is important from the clinical point of view, since the onset of $\mathrm{ASDz}$ may require treatment, including surgery.
In the classic Hilibrand study from 1999, there was a 2.9\% annual risk and a 26\% 10-year risk of ASDz occurrence [2]. Much more frequent occurrence of ASDeg than of ASDz has been proven. Depending on the test method, the values are 16-71\% for ASDeg and 2-43\% for ASDz, respectively. At the same time, such a large difference in the published results depends on the type of radiological examination used to diagnose ASDeg. There is a significant increase in diagnoses using MRI compared to RTG [3-9].

The Hilibrand study indicates that the risk factors for ASDz are age, abnormal segmental mobility, and pre-existing disease. The ongoing degenerative process has been identified as the most likely cause of its occurrence [2]. 
There is little data regarding the biomechanics of the cervical spine following ACDF, and most of what there is covers changes in segments adjacent to the stabilisation. The first of the in vivo studies, consisting of the evaluation of static X-ray images, assessed the occurrence of subluxation of the segments adjacent to ACDF. An indirect conclusion was drawn about the increased mobility of adjacent segments after stating their instability in 14 of the 21 analysed cases of interbody fusions [10]. Recent studies have shown a subtle increase in the range of motion (ROM) of adjacent segments. The changes were more pronounced at the segments above the spondylodesis [11-13]. Another study showed no change in the total ROM of adjacent levels after ACDF; however, an increase in flexion ROM and a decrease in extension over stabilisation and inverse distribution below the spondylodesis were observed [14]. In addition, an increase in ROM of segments adjacent to ACDF has been demonstrated in vivo, compared to artificial disc replacement (ADR) [15].

Studies carried out on specimens taken from cadavers showed an increase in the mobility of segments adjacent to the stabilisation. An increase in ROM was found at both levels adjacent to the stabilisation during flexion, extension, rotation and side flexion, with a change almost double in the segment above [16]. Another study showed an increase in ROM on both adjacent segments during flexion and extension, by $31 \%$ above and $34 \%$ below [17]. Another experiment showed a $19 \%$ increase in ROM at the segment under the stabilisation during extension [18].

Studies carried out on specimens taken from cadavers have also shown that the pressure inside the intervertebral discs adjacent to ACDF increases during mechanical loads. At flexion, a 73\% increase in pressure was found above, and $45 \%$ below, the stabilisation [18]. Another study indicated a $48 \%$ increase in horizontal pressure over spondylosis during flexion and extension, and 125\% below during flexion, extension, rotation and lateral flexion [19]. During simulation of the conditions of sagittal balance disturbances, a subsequent increase of loads transmitted by adjacent segments has been demonstrated [20].

A relationship between the length of stabilisation and the occurrence of ASDeg and ASDz has been demonstrated. It is estimated that single-level or two-level ACDF is associated with a $5.5 \%$ risk of $\mathrm{ASDz}$, while multilevel fusion has a $2.6 \%$ risk $[2,21]$.

In addition, differences in the incidence of ASDeg between ACDF and ADR have been widely analysed. Slightly lower rates of ASDeg have been identified in patients undergoing ADR as ACDF [22-28]. However, no significant differences were found in the clinical condition of the patients nor, most importantly, in the ASDz occurrence [22, 25, 28-31].

Studies on ASDeg and ASDz suggest their multifactorial aetiology. At the same time, most researchers have supported the theory that the primary degenerative process is a factor causing their occurrence.
Very few studies have assessed the biomechanics of the entire cervical spine after ACDF, and reports are contradictory. Some of the available studies assessing the mobility of the cervical spine after ACDF postulate its increase $[32,33]$. The first study showed an increase in flexion by $16 \%$ and lateral bending by $53 \%$ [32]; the second, an increase in ROM in the sagittal, frontal and axial planes by $14 \%, 13 \%$, and $10 \%$. This change did not occur immediately after the surgery, but rather between months three and six of observation [33]. In both studies, no statistically significant differences in the improvement of ROM between groups with different length of spondylodesis were found $[32,33]$. Other studies assessing total ROM have shown that cervical mobility after ACDF decreases, and most likely also changes over time $[12,34]$. The first of these showed that flexion and extension of the neck decreases by $43 \%$ and $29 \%$ after three months, and by another $14 \%$ and $37 \%$ after six months [34]. The second study also proved that the total cervical ROM decreases. The change depends on the length of the spondylodesis performed. Single-level ACDF was associated with a reduction in ROM in a 3-month follow-up and its return to preoperative values over 6-12 months. In the case of operations on two segments, the reduction in ROM was maintained during the same observation [12].

The aim of our study was to make a comprehensive assessment of the global and segmental ROM of the cervical spine after ACDF.

\section{Material and methods}

28 patients who underwent ACDF for cervical spondylosis at the Department of Neurosurgery and Paediatric Neurosurgery at the Pomeranian Medical University in Szczecin from March 2012 to June 2013 were examined. The retrospective study protocol was approved by the Institutional Review Board. All patients gave informed consent for treatment and additional tests.

The group consisted of 22 women and six men. The average age was 51 years (31-61, SD 7.69). All patients were operated on by the same neurosurgeon, Prof. Leszek Sagan. PEEK parallel interbody cages and titanium lordotic anterior plates were used. The study was divided into two stages. The first (preoperative) took place on the day preceding the surgery in 28 patients included in the assessment. The second (postoperative) took place with routine outpatient follow-up after an average of 38 months (11-46, SD 7.83) in 24 patients. The decreasing number of patients included in subsequent stages of the study resulted from the difficulty of continuing regular follow-up visits. The missing data was supplemented by substituting the arithmetic mean of individual parameters. The patients were divided into groups depending on the length of spondylosis, and on the onset of degeneration of the adjacent level.

Classic X-ray images taken in clinical practice were used for the analysis. AP and lateral images taken at each stage of the study were evaluated. All images were obtained using an 
AXIOM Aristis FX digital RTG camera (Siemens Healthcare). The patients were placed in Morvan's standard position for sagittal imaging. The patients assumed a natural, upright posture, standing barefoot, with their feet slightly apart, with straight knees, with their upper limbs hanging down freely. [35]. The posture was not modified by raising their hands on the photo projection supports. Functional images were obtained by full flexion and extension of the neck in lateral projections.

The ASDeg was found on the basis of lateral X-ray images taken in the postoperative stage by changes classified by Hilibrand: narrowing of the interbody space and the presence of osteophytes directed to the spinal canal [2]. However, they were not graded.

Global mobility was calculated on the basis of the difference between the curvature angles $\mathrm{C} 1-\mathrm{C} 7, \mathrm{C} 1-\mathrm{C} 2, \mathrm{C} 2-\mathrm{C}$, $\mathrm{C} 1-\mathrm{C} 4$ and $\mathrm{C} 4-\mathrm{C} 7$ in the static image and the angles measured in the flexion or extension. The total value was obtained by the sum of the two values obtained. The widely recognised Cobb angle method was used to measure curvature [36-40]. This method involves running four straight lines. Depending on the analysed parts, horizontals run between the anterior and posterior $\mathrm{C} 1$ nodules, parallel to the lower endplate of C2, C4 or C7. Then vertical straight lines are perpendicular to the appropriate horizontal ones, and the angle formed by their intersection determines the value of curvature.

The segment setting angle was assessed on the basis of straight lines parallel to the endplates of the respective vertebral bodies. The segmental mobility of levels above and below fusion was calculated on the basis of the difference between the angle measured in the static image and the angles measured in the flexion or extension. The total value was obtained by the sum of the two values obtained.

The draughting of specified lines and the calculation of angles were made with the Surgimap program (Nemaris Inc.) distributed with a freeware licence. The algorithms included in the program allow precise and repeatable determination of spinal osteometric parameters [41, 42].

Descriptive statistics were used in the statistical analysis, where mean, standard deviation, minimum and maximum values were calculated. Arithmetic average method was used to fill in the missing data. The assumption about the normality of the distribution of quantitative variables was checked using the Shapiro-Wilk test. The differences between the values of the collected features before and after the operation were calculated using Friedman's ANOVY and post-hoc tests. Correlations were established using the Pearson linear correlation coefficient. The results were considered significant at $\mathrm{p}<0.05$. The calculations were carried out with the Statistica 12 program (StatSoft).

\section{Results}

Most often, $57 \%$ of ACDF was performed on two segments of the cervical spine. The least was on one level, and the most, three, in $29 \%$ and $14 \%$ of patients, respectively. The most often operated on segments were $\mathrm{C} 5 / \mathrm{C} 6 / \mathrm{C} 7$ in nine patients, and $\mathrm{C} 4 /$ $\mathrm{C} 5 / \mathrm{C} 6$ in seven. The highest operated level was $\mathrm{C} 4 / \mathrm{C} 5$, and the lowest was $\mathrm{C} 7 / \mathrm{Th} 1$ in 12 patients and one patient, respectively.

\section{Global motion}

The average total C2-C7 ROM was preoperatively $45.88^{\circ}$ (23-65, SD 12.81) and postoperatively $35.33^{\circ}(15-65$, SD 13.53). $\mathrm{C} 1-\mathrm{C} 7$ values were $57.92^{\circ}(31-84, \mathrm{SD} 13.49)$ respectively in the first stage of the study and $46.67^{\circ}(16-60$, SD 11.95) in the second. C1-C2 were $15.38^{\circ}$ (5-33, SD 7.21) preoperatively and $16.13^{\circ}(4-64, \mathrm{SD} 12.11)$ postoperatively. C1-C4 were $29.46^{\circ}(12-43$, SD 8.23$)$ in the first stage and $29.83^{\circ}(10-42$, SD 9.19) in the second. C4-C7 were $27.31^{\circ}$ (12-47, SD 10.35) preoperatively and $17.04^{\circ}$ (4-36, SD 7.95) postoperatively.

A statistically significant difference was found in the total mobility of C2-C7, C1-C7, and C4-C7 after ACDF. C2C7 ROM decreased by $23 \%(\mathrm{p}=0.003), \mathrm{C} 1-\mathrm{C} 7$ by $20 \%(\mathrm{p}=$ $0.002)$, and $\mathrm{C} 4-\mathrm{C} 7$ by $38 \%(\mathrm{p}<0.001)$. However, these changes occurred by reducing the extension ROM on $\mathrm{C} 2-\mathrm{C} 7$ by $33 \%$ ( $\mathrm{p}=0.035)$, on $\mathrm{C} 1-\mathrm{C} 7$ by $31 \%(\mathrm{p}=0.006)$, and on $\mathrm{C} 4-\mathrm{C} 7$ by $12 \%(\mathrm{p}=0.002)$. No statistically significant difference in the range of the flexion ROM was found in any of the examined sections. Furthermore, no significant changes in vertebrobasilar joint mobility were revealed. Detailed values of the total ROM of the studied sections, its components and $\mathrm{p}$ values for the differences before and after ACDF are set out in Table 1. Figure 1 shows the reduction of the $\mathrm{C} 2-\mathrm{C} 7$ extension ROM.

In the analysis of the results divided into groups depending on the number of fused segments, only statistically significant results are shown below. After spondylodesis at one level, total ROM C1-C2 decreased by $45 \%(\mathrm{p}=0.005)-15.29^{\circ}(8-21, \mathrm{SD}$ $4.42)$ vs $8.40^{\circ}(4-14, \mathrm{SD} 4.16)$. In the case of two-level surgeries, total ROM C1-C7 after ACDF decreased by $20 \%$ ( $\mathrm{p}=0.006)-$ $56.27^{\circ}(37-75$, SD 12.14$)$ vs $44.81^{\circ}$ (17-66, SD 12.04), C2-C7 by $29 \%(\mathrm{p}=0.001)-43.53^{\circ}(23-57, \mathrm{SD} 12.18)$ vs $31.00^{\circ}(15-51$, SD 10.98), and C4-C7 by $41 \%(\mathrm{p}<0.001)-26.30^{\circ}(13-42$, SD 9.54) vs $15.44^{\circ}(7-28$, SD 5.25). There was also a reduction in extension ROM C1-C7 after ACDF by $30 \%(\mathrm{p}=0.047)-25.00^{\circ}$ (9-42, SD 10.99) vs $17.44^{\circ}$ (2-37, SD 11.11) and C4-C7 by 64\% $(\mathrm{p}=0.013)-26.27^{\circ}\left(13-42\right.$, SD 9.54) vs $9.44^{\circ}(3-16$, SD 4.43). Moreover, flexion ROM C4-C7 decreased by $29 \%(\mathrm{p}=0.020)-$ $15.40^{\circ}\left(5-32\right.$, SD 9.04) vs $10.87^{\circ}$ (1-25, SD 7.05). After ACDF on three segments, total ROM C4-C7 decreased by $67 \%$ ( $\mathrm{p}=$ $0.011)-30.75^{\circ}\left(17-47\right.$, SD 13.12) vs $10.00^{\circ}$ (4-18, SD 7.21).

Flexion ROM C2-C7 after ACDF for single-level fusions compared to two-level was $75 \%$ higher $(\mathrm{p}=0.046)-33.20^{\circ}$ (22-53, SD 12.15) vs $18.94^{\circ}$ (4-36, SD 8.50). Total ROM $\mathrm{C} 2-\mathrm{C} 7$ after ACDF for single-level fusions compared to two-level was $67 \%$ higher $(\mathrm{p}=0.018)-51.80^{\circ}(46-65$, SD $8.04)$ vs $31.00^{\circ}$ (16-51, SD 10.98) (Tab. 2). Extension ROM C1-C2 after ACDF for single-level fusions compared to twolevel was $74 \%$ lower $(\mathrm{p}=0.031)-2.80^{\circ}(1-8$, SD 2.77) vs $10.90^{\circ}$ (1-20, SD 11.00). Total ROM C1-C2 after ACDF for single-level fusions compared to two-level was $57 \%$ lower (p 
Table 1: Descriptive statistics for parameters of cervical spine mobility and $p$ values for differences before and after ACDF. Differences in bold are statistically significant

\begin{tabular}{|c|c|c|c|c|c|}
\hline Feature $\left[{ }^{\circ}\right]$ & mean & $\min$ & $\max$ & SD & $\mathbf{p}$ \\
\hline ROM C2-C7 flexion preop. & 25.54 & 3.0 & 520 & 12.10 & $p=0.315^{* *}$ \\
\hline ROM C2-C7 flexion postop. & 21.63 & 4.0 & 53.0 & 10.73 & \\
\hline ROM C2-C7 extension preop. & 20.35 & 1.0 & 46.0 & 14.19 & $p=0.035^{* *}$ \\
\hline ROM C2-C7 extension postop. & 13.71 & 1.0 & 39.0 & 9.70 & \\
\hline ROM C2-C7 total preop. & 45.88 & 23.0 & 65.0 & 12.81 & $p=0.003^{* *}$ \\
\hline ROM C2-C7 total postop. & 35.33 & 15.0 & 65.0 & 13.53 & \\
\hline ROM C1-C7 flexion preop. & 31.42 & 4.0 & 55.0 & 13.83 & $p=0.613^{* *}$ \\
\hline ROM C1-C7 flexion postop. & 28.50 & 10.0 & 49.0 & 9.17 & \\
\hline ROM C1-C7 extension preop. & 26.50 & 9.0 & 53.0 & 12.27 & $p=0.006^{* *}$ \\
\hline ROM C1-C7 extension postop. & 18.17 & 2.0 & 37.0 & 9.66 & \\
\hline ROM C1-C7 total preop. & 57.92 & 31.0 & 84.0 & 13.49 & $p=0.002^{* *}$ \\
\hline ROM C1-C7 total postop. & 46.67 & 17.0 & 66.0 & 11.95 & \\
\hline ROM C1-C2 flexion preop. & 7.62 & 0.0 & 22.0 & 5.30 & $p=0.714^{* *}$ \\
\hline ROM C1-C2 flexion postop. & 7.58 & 0.0 & 19.0 & 5.01 & \\
\hline ROM C1-C2 extension preop. & 7.77 & 1.0 & 23.0 & 5.05 & $p=0.514^{*}$ \\
\hline ROM C1-C2 extension postop. & 8.54 & 0.0 & 48.0 & 9.64 & \\
\hline ROM C1-C2 total preop. & 15.38 & 5.0 & 33.0 & 7.21 & $P=0.855^{*}$ \\
\hline ROM C1-C2 total postop. & 16.13 & 4.0 & 64.0 & 12.11 & \\
\hline ROM C1-C4 flexion preop. & 16.65 & 2.0 & 30.0 & 8.36 & $p=0.656^{* *}$ \\
\hline ROM C1-C4 flexion postop. & 17.50 & 2.0 & 37.0 & 8.62 & \\
\hline ROM C1-C4 extension preop. & 12.81 & 1.0 & 26.0 & 7.30 & $p=0.744^{* *}$ \\
\hline ROM C1-C4 extension postop. & 12.33 & 2.0 & 30.0 & 7.22 & \\
\hline ROM C1-C4 total preop. & 29.46 & 12.0 & 43.0 & 8.23 & $p=0.863^{* *}$ \\
\hline ROM C1-C4 total postop. & 29.83 & 10.0 & 42.0 & 9.19 & \\
\hline ROM C4-C7 flexion preop. & 14.81 & 2.0 & 32.0 & 8.49 & $p=0.152^{* *}$ \\
\hline ROM C4-C7 flexion postop. & 11.00 & 2.0 & 25.0 & 6.46 & \\
\hline ROM C4-C7 extension preop. & 12.50 & 0.0 & 33.0 & 9.74 & $p=0.002 * *$ \\
\hline ROM C4-C7 extension postop. & 11.00 & 2.0 & 25.0 & 6.46 & \\
\hline ROM C4-C7 total preop. & 27.31 & 12.0 & 47.0 & 10.35 & $p<0.001 * *$ \\
\hline ROM C4-C7 total postop. & 17.04 & 4.0 & 36.0 & 7.95 & \\
\hline
\end{tabular}

${ }^{*}$ Wilcoxon test ${ }^{* *}$ Student'st test

$=0.029)-8.40^{\circ}(4-14$, SD 4.16$)$ vs $19.50^{\circ}(7-33$, SD 13.43). Flexion ROM C4-C7 after ACDF decreased with the number of segments subjected to spondylodesis. Among the two-level fusions it was $52 \%$ smaller $(\mathrm{p}=0.021)-19.80^{\circ}(3-25$, SD $4.76)$ vs $9.44^{\circ}(3-16$, SD 4.43$)$, and on three-level, smaller by $76 \%(\mathrm{p}=0.006)-19.80^{\circ}(3-25$, SD 4.76$)$ vs $4.67^{\circ}(2-9$, SD 3.79 ) than the group which had a single segment operated on.

In the analysis of results divided into groups depending on the occurrence of ASDeg, no statistically significant differences were found in the tested parameters.

\section{Segmental motion}

The mean, total, segmental ROM above ACDF was preoperatively $11.12^{\circ}\left(3-17\right.$, SD 4.26), and postoperatively $9.04^{\circ}$
(1-18, SD 4.96). For the segment located below ACDF, these values were $7.52^{\circ}(1-16$, SD 3.91) in the first stage of the study and $6.96^{\circ}(1-19$, SD 4.19) in the second. There was no statistically significant difference in segmental motion of the levels adjacent to ACDF in the population without division into groups.

In the analysis of the results by groups depending on the occurrence of ASDeg, only statistically significant results are shown below. In the group of patients without ASDeg, the total, segmental ROM above spondylodesis decreased by $31 \%$ ( $\mathrm{p}=$ 0.020 ), with the change occurring by reducing the extension ROM of the segment located above spondylodesis by $41 \%$ ( $\mathrm{p}=$ 0.041). In turn, patients with ASDeg were characterised by $73 \%$ greater postoperative extension ROM of the segment above the stabilisation compared to the group without ASDeg $(p=0.032)$. 


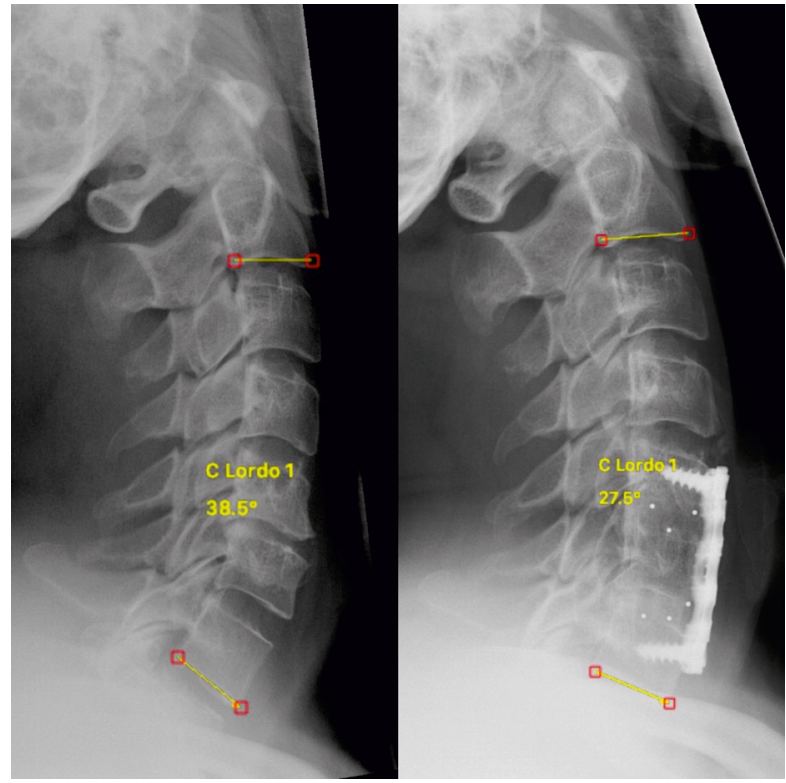

Figure 1. Dynamic, lateral, pre- and postoperative X-rays showing reduction of $\mathrm{C} 2-\mathrm{C} 7$ extension $\mathrm{ROM}$ after $\mathrm{ACDF}$

Table 2: Post-hoc $p$-values for differences between number of levels for total ROM C2-C7 after ACDF (Kruskal-Wallis ANOVA $p=0.019$ ). Differences in bold are statistically significant

\begin{tabular}{|lccc|}
\hline $\begin{array}{l}\text { Number } \\
\text { of treated levels } \\
\text { (mean } \pm \text { SD) }\end{array}$ & R: $\mathbf{2 0 . 4 0 0}$ & R: $\mathbf{1 0 . 4 6 9}$ & R: $\mathbf{1 0 . 1 6 7}$ \\
\hline $\mathbf{1}(51.80 \pm 8.04)$ & & $\mathbf{0 . 0 1 8}$ & 0.143 \\
\hline $\mathbf{2}(31.00 \pm 10.98)$ & $\mathbf{0 . 0 1 8}$ & & 1.000 \\
\hline $\mathbf{3}(31.00 \pm 14.73)$ & 0.143 & 1.000 & \\
\hline
\end{tabular}

\section{Discussion}

\section{Global motion}

In a study using a motion analyser, it was shown that the mobility of flexion and extension of the neck after ACDF decreases by $43 \%$ and $29 \%$ after three months, and by another $14 \%$ and $37 \%$ after six months [34]. Assessment of X-rays has proved that the total ROM of the cervical spine decreases, and this change depends on the length of the spondylodesis performed. Single-level ACDF showed a ROM reduction in a three-month follow-up and a return to preoperative values over 6-12 months. In the case of operations on two segments, the ROM reduction was maintained during the same observation [12].

On the other hand, in a study using a motion analyser, increases were found in neck flexion ROM and frontal plane motions after ACDF by $16 \%$ and $53 \%$, respectively [32]. It was proved by analysing data from a similar device that the ROM of the cervical spine increases in the sagittal, frontal and axial planes by $14 \%, 13 \%$, and $10 \%$, respectively. This change did not occur immediately after surgery, but after between three and six months [33].

The need for further research into the global mobility of the cervical spine after ACDF is demonstrated by these generally contradictory results. A direct ACDF effect in this study was found by the reduction of global ROM in the sagittal plane. This thesis is confirmed by a $40 \%$ smaller total, postoperative ROM C2-C7 versus two-to-one-level operations and a reduction of postoperative flexion ROM C4-C7, together with the rising number of segments subjected to ACDF. No significant differences were recorded in the global mobility of the cervical spine between the groups with and without ASDeg.

This indicates, indirectly, that postoperative changes in the global ROM of the cervical spine are not associated with ongoing degenerative processes.

\section{Segmental motion}

The focus of studies on degenerative changes occurring at levels adjacent to stabilisation is the question: is their occurrence associated with the ongoing primary degenerative process, or with biomechanical changes happening after spondylodesis?

Postoperative increase in extension ROM and decrease in flexion ROM of a segment located above ACDF without significantly affecting total ROM has been demonstrated [14]. In turn, an increase was observed in the total ROM segment located above the stabilisation occurring within three months from single-level ACDF and in 6-12 months from dual-level [12]. In studies carried out on specimens taken from cadavers, an increase in the total ROM of adjacent segments to spondylodesis, expressed by an increase in both flexion and extension ROM, was shown $[16,18]$.

The existence of ASDz has been questioned by some authors. No differences in the occurrence of new degenerative changes between patients after ACDF and the healthy population have been shown in studies, including the best-known one by Gore et al. $[3,8,43,44]$. The fact that C5/C6 and C6/ $\mathrm{C} 7$ levels most often undergo spondylotic changes, and have an increased risk of developing ASDz, was demonstrated by Hilibrand et al. in their classic study on ASDeg [2]. This thesis has been re-confirmed in subsequent studies [9, 43, 45]. In addition, a relationship has been demonstrated between age and degenerative changes in the cervical spine. Boden et al found a $14 \%$ incidence below the age of 40 , and $28 \%$ above, by analysing MRI images [43].

The relationship has been considered between mechanical soft tissue damage and the development of degeneration at the adjacent segment. It has been proved that puncture of the intervertebral space (performed for the purpose of Xray verification of the operated level) is associated with the subsequent occurrence of degenerative changes [46]. The location of the anterior plate at least $5 \mathrm{~mm}$ from the adjacent intervertebral disc is associated with a reduced risk of anterior osteophytosis [47, 48]. 
As discussed, a reduction in segmental ROM above spondylodesis after ACDF has been demonstrated in patients without subsequent ASDeg. It has also been proven that the occurrence of ASDeg is associated with a greater postoperative extension ROM of the segment located above the spondylodesis compared to the group without ASDeg.

The obtained results suggest a relationship between the occurrence of ASDeg and the range of motion of the adjacent levels to spondylodesis. However, based on the results of this study, it cannot be determined whether changes in segmental motion are the cause of the new degeneration, or rather its consequence.

\section{Conclusions}

Anterior cervical discectomy with fusion reduces the total mobility of the cervical spine in the sagittal plane. This change occurs by reducing the extension of the neck, and its severity depends on the length of the spondylodesis.

In patients without postoperative adjacent segment degeneration, anterior cervical discectomy with fusion reduces postoperative mobility of the segment above the stabilisation.

The occurrence of adjacent segment degeneration is associated with a greater range of postoperative extension of the segment located above the spondylodesis.

Funding: This paper was prepared without any external source of funding.

Conflicts of interest: The authors report no conflict of interest.

\section{References}

1. Hilibrand AS, Robbins M. Adjacent segment degeneration and adjacent segment disease: the consequences of spinal fusion? Spine J. 2004; 4(6 Suppl): 190S-194S, doi: 10.1016/j.spinee.2004.07.007, indexed in Pubmed: 15541666.

2. Hilibrand AS, Carlson GD, Palumbo MA, et al. Radiculopathy and myelopathy at segments adjacent to the site of a previous anterior cervical arthrodesis. J Bone Joint Surg Am. 1999; 81(4): 519-528, doi: 10.2106/00004623-199904000-00009, indexed in Pubmed: 10225797.

3. Gore DR, Sepic SB, Gardner GM. Roentgenographic findings of the cervical spine in asymptomatic people. Spine (Phila Pa 1976). 1986; 11(6): 521-524, doi: 10.1097/00007632-198607000-00003, indexed in Pubmed: 3787320.

4. Katsuura A, Hukuda S, Saruhashi Y, et al. Kyphotic malalignment after anterior cervical fusion is one of the factors promoting the degenerative process in adjacent intervertebral levels. Eur Spine J. 2001; 10(4): 320-324, doi: 10.1007/s005860000243, indexed in Pubmed: 11563618.

5. Bolesta MJ, Rechtine GR, Chrin AM. One- and two-level anterior cervical discectomy and fusion: the effect of plate fixation. Spine J. 2002; 2(3): 197-203, doi: 10.1016/s1529-9430(02)00186-9, indexed in Pubmed: 14589493.

6. Greiner-Perth R, Allam Y, El-Saghir $\mathrm{H}$, et al. Analysis of reoperations after surgical treatment of degenerative cervical spine disorders: a report on 900 cases. Cent Eur Neurosurg. 2009; 70(1): 3-8, doi: 10.1055/s-0028-1082061, indexed in Pubmed: 19191203.

7. Marotta N, Landi A, Tarantino R, et al. Five-year outcome of stand-alone fusion using carbon cages in cervical disc arthrosis. Eur Spine J. 2011; 20 Suppl 1: S8-12, doi: 10.1007/s00586-011-1747-0, indexed in Pubmed: 21404034.

8. Song KJ, Choi BW, Jeon TS, et al. Adjacent segment degenerative disease: is it due to disease progression or a fusion-associated phenomenon? Comparison between segments adjacent to the fused and non-fused segments. Eur Spine J. 2011; 20(11): 1940-1945, doi: 10.1007/s00586-011-1864-9, indexed in Pubmed: 21656051.

9. Komura S, Miyamoto $\mathrm{K}$, Hosoe $\mathrm{H}$, et al. Lower incidence of adjacent segment degeneration after anterior cervical fusion found with those fusing C5-6 and C6-7 than those leaving C5-6 or C6-7 as an adjacent level. J Spinal Disord Tech. 2012; 25(1): 23-29, doi: 10.1097/ BSD.0b013e31820bb1f8, indexed in Pubmed: 21430572.

10. Döhler JR, Kahn MR, Hughes SP. Instability of the cervical spine after anterior interbody fusion. A study on its incidence and clinical significance in 21 patients. Arch Orthop Trauma Surg. 1985; 104(4): $247-$ 250, doi: 10.1007/BF00450219, indexed in Pubmed: 4084040.

11. Park DK, Lin EL, Phillips FM. Index and adjacent level kinematics after cervical disc replacement and anterior fusion: in vivo quantitative radiographic analysis. Spine (Phila Pa 1976). 2011; 36(9): 721 730, doi: 10.1097/BRS.0b013e3181df10fc, indexed in Pubmed: 20543765.

12. Chien A, Lai DM, Wang SF, et al. Differential segmental motion contribution of single- and two-level anterior cervical discectomy and fusion. Eur Spine J. 2015; 24(12): 2857-2865, doi: 10.1007/s00586-0153900-7, indexed in Pubmed: 25860996.

13. Gornet MF, Burkus JK, Shaffrey ME, et al. Cervical disc arthroplasty with PRESTIGE LP disc versus anterior cervical discectomy and fusion: a prospective, multicenter investigational device exemption study. J Neurosurg Spine. 2015; 23(5): 558-573, doi: 10.3171/2015.1.SPINE14589, indexed in Pubmed: 26230424.

14. Anderst WJ, Lee JY, Donaldson WF, et al. Six-degrees-of-freedom cervical spine range of motion during dynamic flexion-extension after single-level anterior arthrodesis: comparison with asymptomatic control subjects. J Bone Joint Surg Am. 2013; 95(6): 497-506, doi: 10.2106/ JBJS.K.01733, indexed in Pubmed: 23515984.

15. McDonald CP, Chang V, McDonald M, et al. Three-dimensional motion analysis of the cervical spine for comparison of anterior cervical decompression and fusion versus artificial disc replacement in 17 patients: clinical article. J Neurosurg Spine. 2014; 20(3): 245-255, doi: 10.3171/2013.11.SPINE13392, indexed in Pubmed: 24359000.

16. Cho BoY, Lim J, Sim HBo, et al. Biomechanical analysis of the range of motion after placement of a two-level cervical ProDisc-C versus hybrid construct. Spine (Phila Pa 1976). 2010; 35(19): 1769-1776, doi: 10.1097/BRS.0b013e3181c225fa, indexed in Pubmed: 20395885.

17. Prasarn ML, Baria D, Milne E, et al. Adjacent-level biomechanics after single versus multilevel cervical spine fusion. J Neurosurg Spine. 2012; 16(2): 172-177, doi: 10.3171/2011.10.SPINE11116, indexed in Pubmed: 22136389.

18. Eck JC, Humphreys SC, Lim TH, et al. Biomechanical study on the effect of cervical spine fusion on adjacent-level intradiscal pressure and segmental motion. Spine (Phila Pa 1976). 2002; 27(22): 2431-2434, doi: 10.1097/00007632-200211150-00003, indexed in Pubmed: 12435970.

19. Dmitriev AE, Cunningham BW, Hu N, et al. Adjacent level intradiscal pressure and segmental kinematics following a cervical 
total disc arthroplasty: an in vitro human cadaveric model. Spine (Phila Pa 1976). 2005; 30(10): 1165-1172, doi: 10.1097/01. brs.0000162441.23824.95, indexed in Pubmed: 15897831.

20. Patwardhan AG, Khayatzadeh S, Nguyen NL, et al. Is Cervical Sagittal Imbalance a Risk Factor for Adjacent Segment Pathomechanics After Multilevel Fusion? Spine (Phila Pa 1976). 2016; 41(10): E580E588, doi: 10.1097/BRS.0000000000001316, indexed in Pubmed: 26630432.

21. Ishihara $\mathrm{H}$, Kanamori $\mathrm{M}$, Kawaguchi $\mathrm{Y}$, et al. Adjacent segment disease after anterior cervical interbody fusion. Spine J. 2004; 4(6): 624-628, doi: 10.1016/j.spinee.2004.04.011, indexed in Pubmed: 15541693.

22. Bartels RH, Donk R, Verbeek ALM. No justification for cervical disk prostheses in clinical practice: a meta-analysis of randomized controlled trials. Neurosurgery. 2010; 66(6): 1153-60; discussion 1160, doi: 10.1227/01.NEU.0000369189.09182.5F, indexed in Pubmed: 20421840.

23. Burkus JK, Traynelis VC, Haid RW, et al. Long-term clinical and radiographic outcomes of cervical disc replacement with the Prestige disc: results from a prospective randomized controlled clinical trial. J Neurosurg Spine. 2010; 13(3): 308-318, doi: 10.3171/2010.3.SPINE09513, indexed in Pubmed: 20809722.

24. Maldonado CV, Paz RDR, Martin CB. Adjacent-level degeneration after cervical disc arthroplasty versus fusion. Eur Spine J. 2011; 20 Suppl 3: 403-407, doi: 10.1007/s00586-011-1916-1, indexed in Pubmed: 21796395.

25. McAfee PC, Reah C, Gilder K, et al. A meta-analysis of comparative outcomes following cervical arthroplasty or anterior cervical fusion: results from 4 prospective multicenter randomized clinical trials and up to 1226 patients. Spine (Phila Pa 1976). 2012; 37(11): 943952, doi: 10.1097/BRS.0b013e31823da169, indexed in Pubmed: 22037535.

26. Nunley PD, Jawahar A, Kerr EJ, et al. Factors affecting the incidence of symptomatic adjacent-level disease in cervical spine after total disc arthroplasty: 2- to 4-year follow-up of 3 prospective randomized trials. Spine (Phila Pa 1976). 2012; 37(6): 445-451, doi: 10.1097/ BRS.0b013e31822174b3, indexed in Pubmed: 21587111.

27. Coric D, Kim PK, Clemente JD, et al. Prospective randomized study of cervical arthroplasty and anterior cervical discectomy and fusion with long-term follow-up: results in 74 patients from a single site. J Neurosurg Spine. 2013; 18(1): 36-42, doi: 10.3171/2012.9.SPINE12555, indexed in Pubmed: 23140129.

28. Gao F, Mao T, Sun W, et al. An Updated Meta-Analysis Comparing Artificial Cervical Disc Arthroplasty (CDA) Versus Anterior Cervical Discectomy and Fusion (ACDF) for the Treatment of Cervical Degenerative Disc Disease (CDDD). Spine (Phila Pa 1976). 2015; 40(23): 1816-1823, doi: 10.1097/BRS.0000000000001138, indexed in Pubmed: 26571063.

29. Mummaneni PV, Burkus JK, Haid RW, et al. Clinical and radiographic analysis of cervical disc arthroplasty compared with allograft fusion: a randomized controlled clinical trial. J Neurosurg Spine. 2007; 6(3): 198-209, doi: 10.3171/spi.2007.6.3.198, indexed in Pubmed: 17355018.

30. Heller JG, Sasso RC, Papadopoulos SM, et al. Comparison of BRYAN cervical disc arthroplasty with anterior cervical decompression and fusion: clinical and radiographic results of a randomized, controlled, clinical trial. Spine (Phila Pa 1976). 2009; 34(2): 101-107, doi: 10.1097/BRS.0b013e31818ee263, indexed in Pubmed: 1911233.

31. Murrey D, Janssen M, Delamarter R, et al. Results of the prospective, randomized, controlled multicenter Food and Drug Administration investigational device exemption study of the ProDisc-C total disc replacement versus anterior discectomy and fusion for the treatment of 1-level symptomatic cervical disc disease. Spine J. 2009; 9(4): 275-286, doi: 10.1016/j.spinee.2008.05.006, indexed in Pubmed: 18774751.

32. Hilibrand AS, Balasubramanian K, Eichenbaum M, et al. The effect of anterior cervical fusion on neck motion. Spine (Phila Pa 1976). 2006; 31(15): 1688-1692, doi: 10.1097/01.brs.0000224165.66444.71, indexed in Pubmed: 16816764.

33. Landers MR, Addis KA, Longhurst JK, et al. Anterior cervical decompression and fusion on neck range of motion, pain, and function: a prospective analysis. Spine J. 2013; 13(11): 1650 1658, doi: 10.1016/j.spinee.2013.06.020, indexed in Pubmed: 24041918.

34. Lee JH, Kim JS, Lee JHo, et al. Comparison of cervical kinematics between patients with cervical artificial disc replacement and anterior cervical discectomy and fusion for cervical disc herniation. Spine J. 2014; 14(7): 1199-1204, doi: 10.1016/j.spinee.2013.08.010, indexed in Pubmed: 24183464.

35. Morvan G, Mathieu P, Vuillemin V, et al. Standardized way for imaging of the sagittal spinal balance. Eur Spine J. 2011; 20 Suppl 5: 602-608, doi: 10.1007/s00586-011-1927-y, indexed in Pubmed: 21830081.

36. Cobb JR. Outlines for the study of scoliosis. In: Edwards, editor. Instructional course lectures of the American Academy of Orthoedic Surgeons. 51948 p. : 261-75.

37. Singer KP, Jones TJ, Breidahl PD. A comparison of radiographic and computer-assisted measurements of thoracic and thoracolumbar sagittal curvature. Skeletal Radiol. 1990; 19(1): 21-26, doi: 10.1007/ BF00197923, indexed in Pubmed: 2326651.

38. Polly DW, Kilkelly FX, McHale KA, et al. Measurement of lumbar lordosis. Evaluation of intraobserver, interobserver, and technique variability. Spine (Phila Pa 1976). 1996; 21(13): 1530-5; discussion 1535, doi: 10.1097/00007632-199607010-00008, indexed in Pubmed: 8817780.

39. Harrison D, Harrison D, Cailliet R, et al. Cobb Method or Harrison Posterior Tangent Method. Spine. 2000; 25(16): 2072-2078, doi: 10.1097/00007632-200008150-00011.

40. Srinivasalu S, Modi HN, Smehta S, et al. Cobb angle measurement of scoliosis using computer measurement of digitally acquired radiographs-intraobserver and interobserver variability. Asian Spine J. 2008; 2(2): 90-93, doi: 10.4184/asj.2008.2.2.90, indexed in Pubmed: 20404962.

41. Akbar M, Terran J, Ames CP, et al. Use of Surgimap Spine in sagittal plane analysis, osteotomy planning, and correction calculation. Neurosurg Clin N Am. 2013; 24(2): 163-172, doi: 10.1016/j. nec.2012.12.007, indexed in Pubmed: 23561555.

42. Lafage R, Ferrero E, Henry JK, et al. Validation of a new computer-assisted tool to measure spino-pelvic parameters. Spine J. 2015; 15(12): 2493-2502, doi: 10.1016/j.spinee.2015.08.067, indexed in Pubmed: 26343243.

43. Boden SD, McCowin PR, Davis DO, et al. Abnormal magnetic-resonance scans of the cervical spine in asymptomatic subjects. A prospective investigation. J Bone Joint Surg Am. 1990; 72(8): 1178-1184, indexed in Pubmed: 2398088.

44. Gore DR. Roentgenographic findings in the cervical spine in asymptomatic persons: a ten-year follow-up. Spine (Phila Pa 1976). 2001; 26(22): 2463-2466, doi: 10.1097/00007632-200111150-00013, indexed in Pubmed: 11707711. 
45. Bohlman HH, Emery SE, Goodfellow DB, et al. Robinson anterior cervical discectomy and arthrodesis for cervical radiculopathy. Long-term follow-up of one hundred and twenty-two patients. J Bone Joint Surg Am. 1993; 75(9): 1298-1307, doi: 10.2106/00004623199309000-00005, indexed in Pubmed: 8408151.

46. Nassr A, Lee JY, Bashir RS, et al. Does incorrect level needle localization during anterior cervical discectomy and fusion lead to accelerated disc degeneration? Spine (Phila Pa 1976). 2009; 34(2): 189-192, doi: 10.1097/BRS.0b013e3181913872, indexed in Pubmed: 19139670.
47. Park JB, Cho YS, Riew KD. Development of adjacent-level ossification in patients with an anterior cervical plate. J Bone Joint Surg Am. 2005; 87(3): 558-563, doi: 10.2106/JBJS.C.01555, indexed in Pubmed: 15741622.

48. Kim HJo, Kelly MP, Ely CG, et al. The risk of adjacent-level ossification development after surgery in the cervical spine: are there factors that affect the risk? A systematic review. Spine (Phila Pa 1976). 2012; 37(22 Suppl): S65-S74, doi: 10.1097/BRS.0b013e31826cb8f5, indexed in Pubmed: 22872223. 